\title{
\#USES
}

science for a changing world

Prepared in cooperation with the

National Oceanic and Atmospheric Administration

\section{Sun-illuminated sea floor topography of Quadrangle 4 in the Stellwagen Bank National Marine Sanctuary off Boston, Massachusetts}

By Page C. Valentine, Tanya S. Unger, and Jessica L. Baker

Geologic Investigations Series Map I-2704

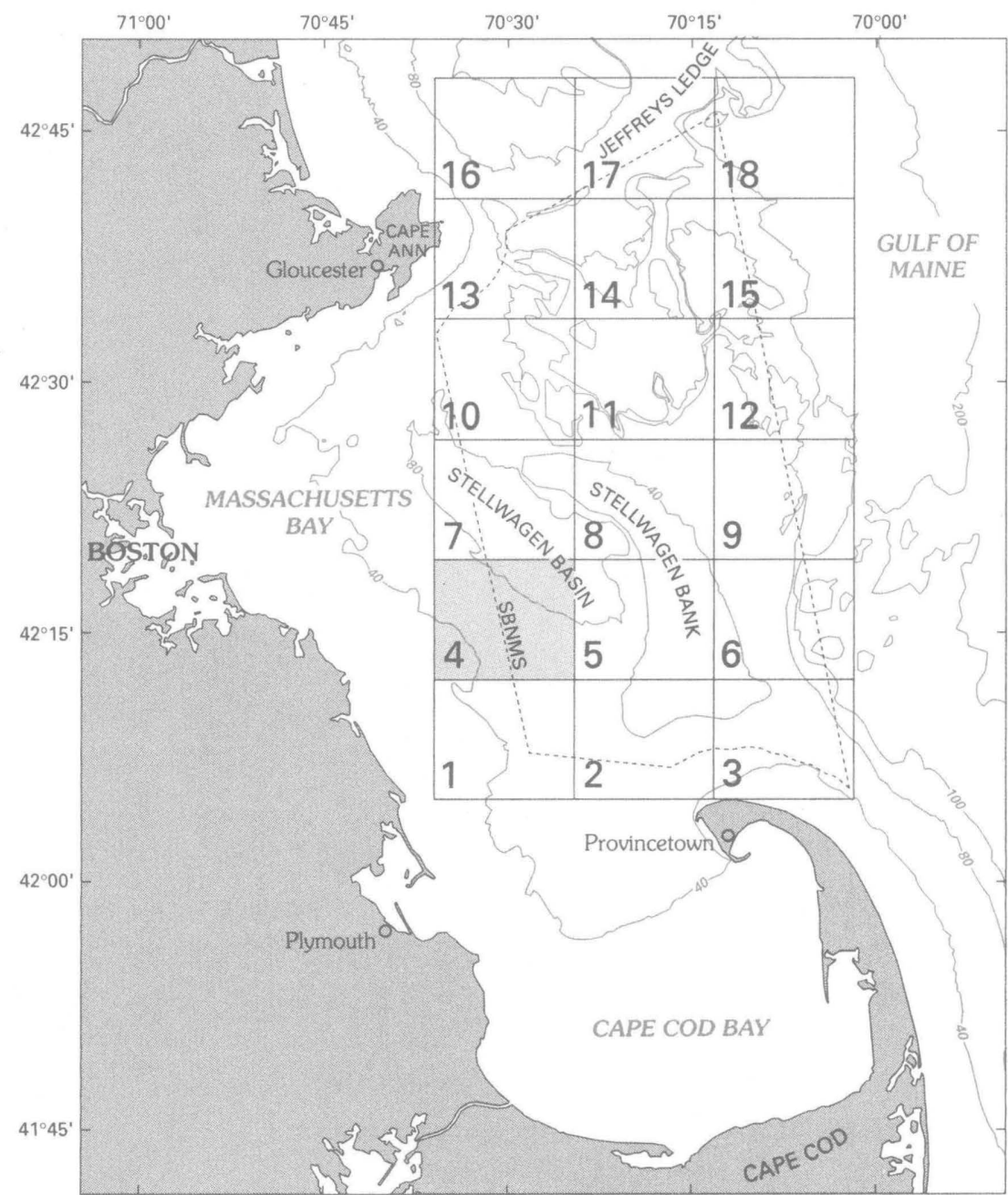

